This is the author's final, peer-reviewed manuscript as accepted for publication. The publisher-formatted version may be available through the publisher's web site or your institution's library.

\title{
Surface roughness in rotary ultrasonic machining: hypotheses and their testing via experiments and simulations
}

W. L. Cong, Z. J. Pei, T. W. Deines, P. F. Zhang, C. Treadwell

How to cite this manuscript

If you make reference to this version of the manuscript, use the following information:

Cong, W. L., Pei, Z. J., Deines, T. W., Zhang, P. F., \& Treadwell, C. (2013). Surface roughness in rotary ultrasonic machining: Hypotheses and their testing via experiments and simulations. Retrieved from http://krex.ksu.edu

\section{Published Version Information}

Citation: Cong, W. L., Pei, Z. J., Deines, T. W., Zhang, P. F., \& Treadwell, C. (2013). Surface roughness in rotary ultrasonic machining: Hypotheses and their testing via experiments and simulations. International Journal of Manufacturing Research, 8(4), 378-393.

Digital Object Identifier (DOI): doi:10.1504/IJMR.2013.057748

Publisher's Link: http://www.inderscience.com/info/inarticle.php?artid=57748

This item was retrieved from the K-State Research Exchange (K-REx), the institutional repository of Kansas State University. K-REx is available at http://krex.ksu.edu 


\title{
Surface roughness in rotary ultrasonic machining: hypotheses and their testing via experiments and simulations
}

\author{
W.L. Cong ${ }^{\text {a }}$, Z.J. Pei ${ }^{\text {a* }}$, T.W. Deines ${ }^{\text {a }}$, P.F. Zhang ${ }^{\text {a }}$ C. Treadwell ${ }^{\text {b }}$ \\ ${ }^{a}$ Department of Industrial and Manufacturing Systems Engineering, Kansas State University, \\ Manhattan, KS 66506, USA \\ ${ }^{\mathrm{b}}$ Sonic-Mill, 7500 Bluewater Road NW, Albuquerque, NM 87121, USA
}

\begin{abstract}
Rotary ultrasonic machining (RUM) is a nontraditional drilling process. It has been used to drill not only brittle but also ductile materials. It was observed that the surface roughness of the drilled hole near the entrance side was better than that near the exit side. However, explanations about this observation could not be found in the literature. This paper aims to provide explanations about this observation. It presents three hypotheses and their testing via experiments and simulations.
\end{abstract}

\section{KEY WORDS}

Grinding, Hypothesis, Machining, Rotary ultrasonic machining, Stainless steel, Surface roughness.

* Corresponding author. Tel.: +1 785532 3436; fax: +1 7855323738.

E-mail address: zpei@ksu.edu (Z.J. Pei). 


\section{Biographical Notes}

W.L. Cong received his Ph.D. degree in industrial engineering from Industrial and Manufacturing Systems Engineering Department at Kansas State University USA. His current research activities are in drilling of high performance materials including advance ceramics, stainless steels, titanium alloys, CFRP composites, as well as CFRP/Ti stacks; lapping of semiconductor wafers; and ultrasonic vibration-assisted pelleting of biomass.

Z.J. Pei received a Ph.D. in Mechanical Engineering from University of Illinois at Urbana-Champaign. He is currently a Professor in the Department of Industrial and Manufacturing Systems Engineering at Kansas State University. He holds three US patents and has published more than 70 journal papers and 100 conference papers. His current research activities include analysis and modeling of silicon wafering processes, traditional and non-traditional machining processes, and energy manufacturing.

T.W. Deines received his B.S. degree from Kansas State University. He is currently an Instructor and Graduate Student in the Industrial and Manufacturing Systems Engineering Department at Kansas State University. His research focuses on energy manufacturing.

P.F. Zhang got his Ph.D. degree in industrial engineering from Kansas State University. He is now a research assistant professor in industrial and manufacturing systems engineering at Kansas State University, USA. His research interests cover RUM of titanium, lapping of semiconductor wafers, and ultrasonic vibration-assisted pelleting of biomass.

C. Treadwell is the President of Sonic Mill. He has over 20 years of experience in designing and making of ultrasonic machines and developing innovative machining processes with ultrasonic technology. 


\section{INTRODUCTION}

Rotary ultrasonic machining (RUM) is a nontraditional machining method and has been used to drill a variety of materials. It has been shown that RUM can effectively drill ceramics (Churi et al., 2007c; 2009; Jiao et al., 2005; Prabhakar, 1992; Zeng et al., 2004), composites (Li et al., 2004; 2005ab; 2007; Cong et al., 2011), titanium (Churi et al., 2005; 2006; 2007ab), and stainless steel (Cong et al., 2009ab; 2010). Figure 1 illustrates RUM. A rotating core drill (as illustrated in Figure 2) with metal-bonded diamond abrasives vibrates in the axial direction at an ultrasonic frequency and feeds towards the workpiece at a constant feedrate or pressure. Coolant is pumped through the core of the drill and washes away the swarf and keeps the tool cool.

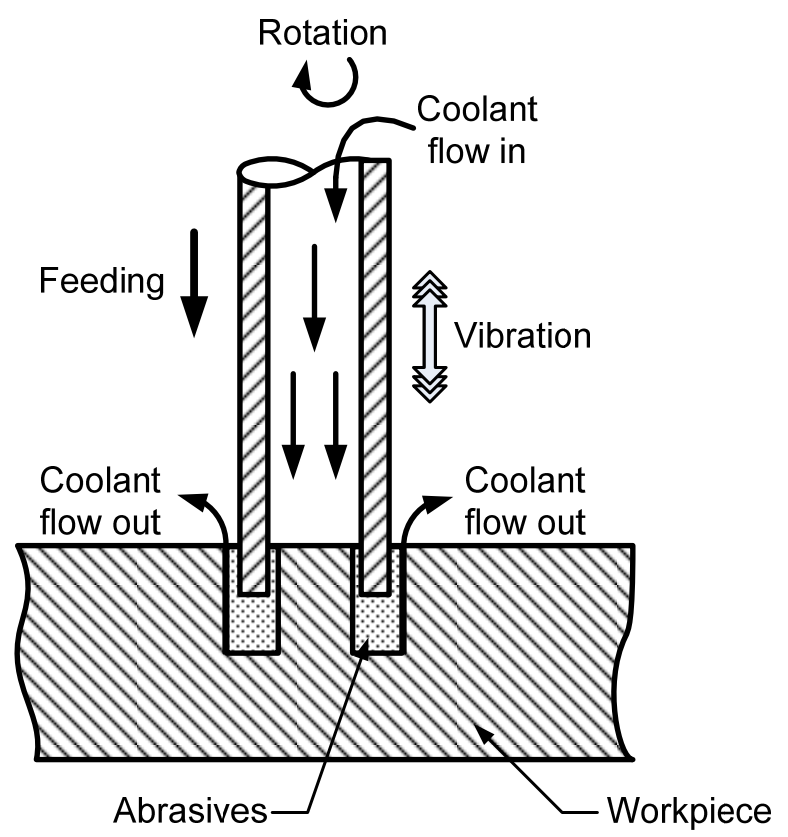

Figure 1 Illustration of RUM. 


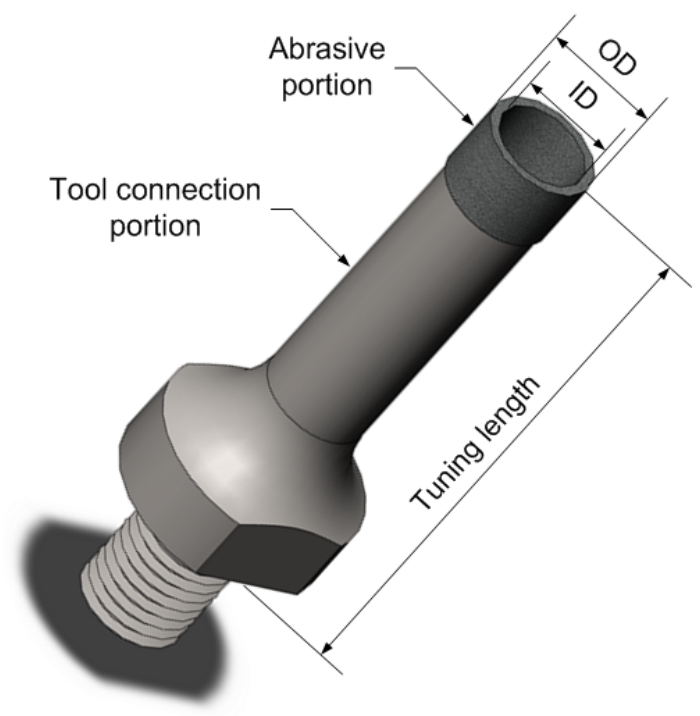

Figure 2 Illustration of the core drill.

Effects of input variables (tool rotation speed; feedrate or constant pressure; ultrasonic vibration amplitude and frequency; diamond type, grit size, and concentration; and bond type for the tool) on surface roughness in RUM of brittle materials (including several types of ceramics) were investigated experimentally (Churi et al., 2007c; 2009; Jiao et al., 2005; Prabhakar, 1992; Zeng et al., 2004). Experimentally-determined relationships between input variables (e.g., tool rotation speed, feedrate, and ultrasonic power) and surface roughness in RUM of ductile materials (titanium and stainless steel) were also reported (Churi et al., 2005; 2006; 2007ab; Cong et al., 2009b; 2010). In addition, it was observed (Cong et al., 2010) when using RUM to drill stainless steel that surface roughness of the machined hole and rod near the entrance side was better than that near the exit side. Figure 3 illustrates the entrance side and exit side of the machined hole 
and rod. Figure 4 shows pictures of machined surfaces at these two locations (near the entrance side and near the exit side). However, explanations about this observation could not be found in the literature. This paper aims to provide explanations about this observation. Such knowledge is important in order to further improve the surface roughness of holes machined by RUM.

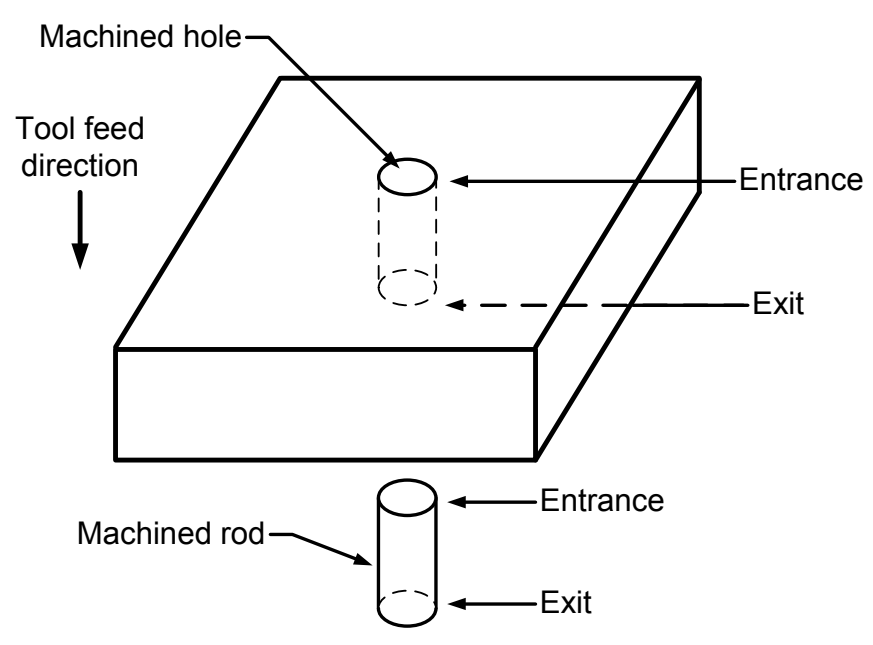

Figure 3 Illustration of entrance and exit sides of machined hole and rod.

This paper presents three hypotheses on why surface roughness near the entrance side is better than that near the exit side, and their testing via experiments and simulations. It is organized in five sections. Each of the next three sections presents one hypothesis and its testing. The last section contains conclusions. 

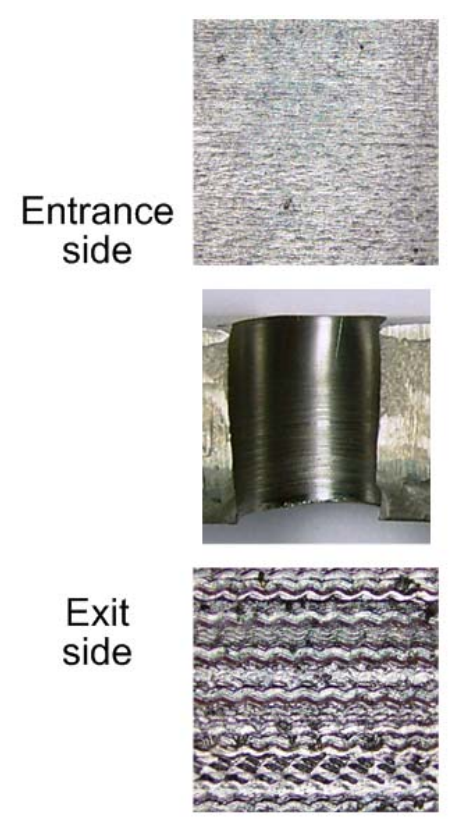

Figure 4 Pictures of machined hole surface by RUM.

\section{HYPOTHESIS 1}

\section{Hypothesis}

Figure 5 shows the four stages of RUM drilling:

(a) The tool is at its starting position;

(b) Drilling starts, the vibrating tool (a core drill with diamond abrasives) is fed into the workpiece;

(c) Drilling ends;

(d) The tool retreats. 


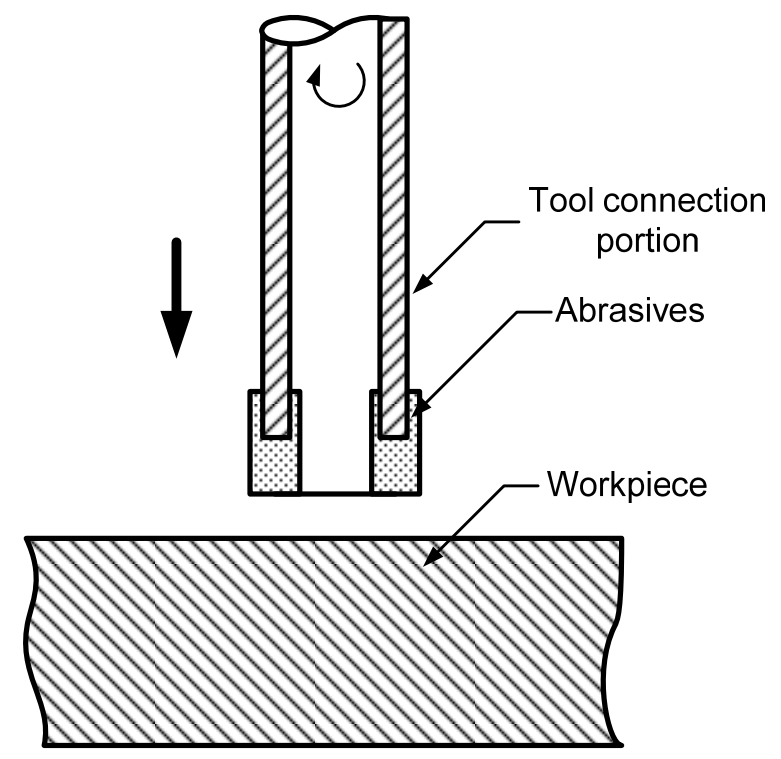

(a) The tool is at its starting position

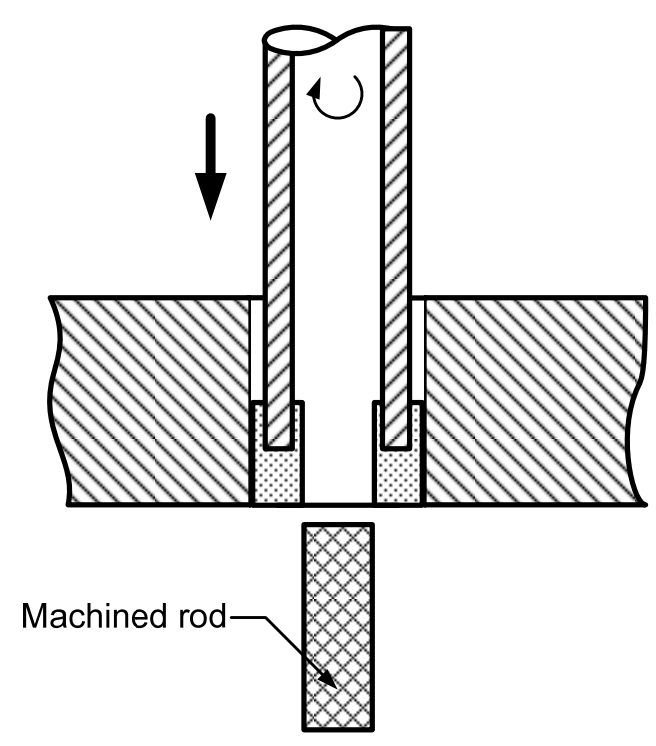

(c) Drilling ends

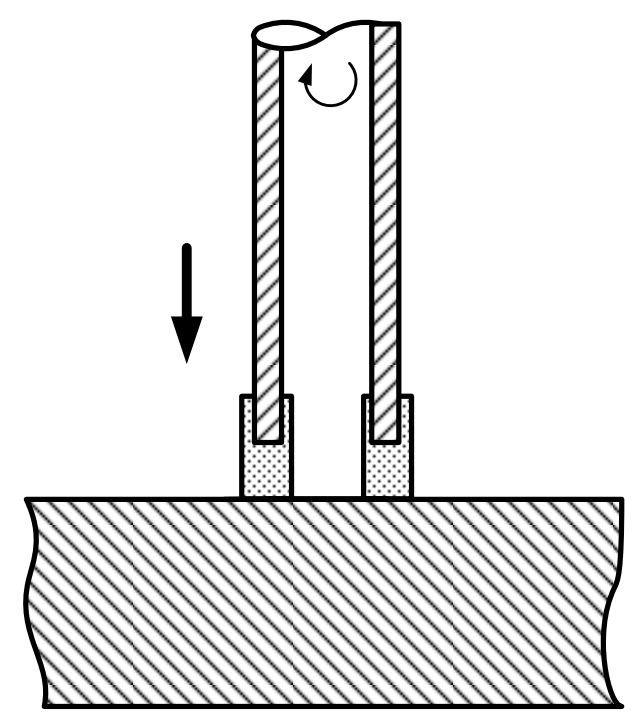

(b) Drilling starts

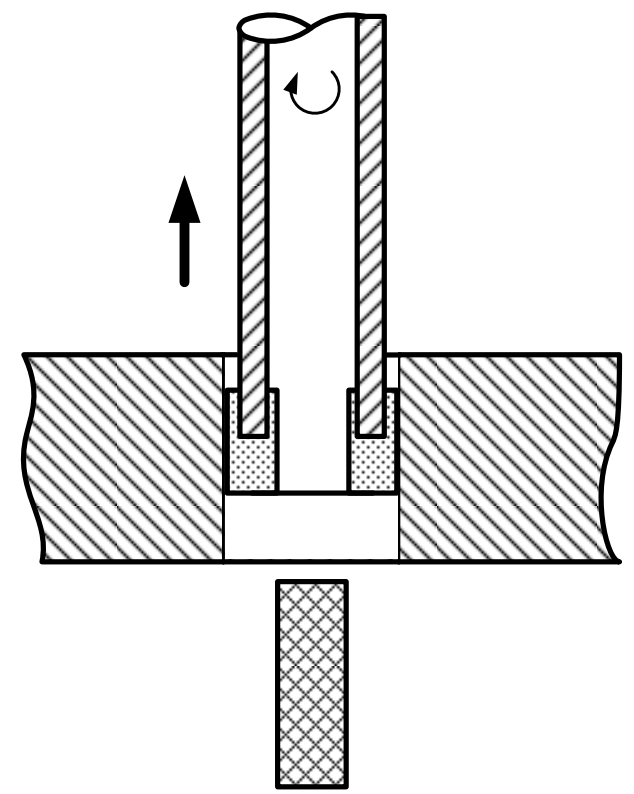

(d) The tool retreats

Figure 5 Illustration of Hypothesis 1. 
After the tool finishes drilling the hole, it retreats to its starting position. As it retreats, the tool still rotates and vibrates, and may grind the wall of the machined hole. The hole surface near the entrance side might be ground again while the tool retreats but the hole surface near the exit side might not. It is hypothesized that this additional grinding is the cause for the difference in surface roughness at the two locations.

\section{Hypothesis testing via experiments}

\section{Experiment set-up}

The experiments were performed on a Sonic-Mill Series 10 RUM machine (Sonic-Mill, Albuquerque, NM, USA). The experiment set-up is shown in Figure 6. The diamond core drills were provided by NBR Diamond tool Corp. (LaGrangeville, NY, USA). The tuning length of these drills was $45.7 \mathrm{~mm}$. Each drill had a connection portion and an abrasive portion. For the abrasive portion, the outer diameter (OD) was $9.59 \mathrm{~mm}$ and the inner diameter (ID) was 7.80 $\mathrm{mm}$. The mesh size of the diamond abrasives was $80 / 100$. The bond type $\mathrm{C}$ (with harder bond material than bond type B) was used. The cutting fluid used was water-soluble Quakercool 6010 (Murdock Industrial Supply Co., Wichita, KS, USA). It was diluted with water at a ratio of 1 to 
14. Other experiment conditions are shown in Table 1. Under each machining conditions, three holes were drilled.

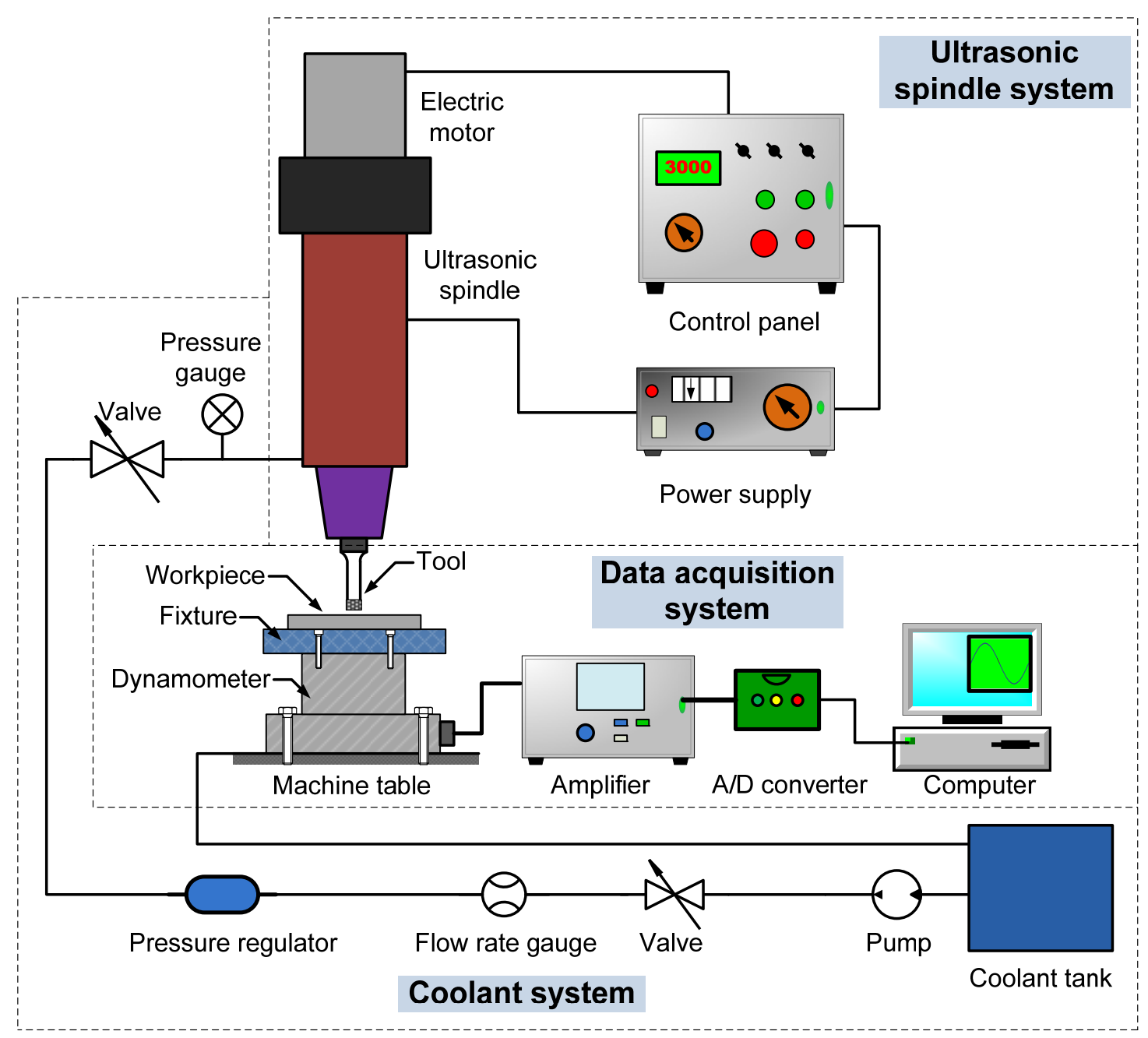

Figure 6 Experiment set-up.

Table 1 Experiment conditions

\begin{tabular}{ll}
\hline Variable & Value \\
\hline Tool rotation speed (rpm) & 3000 \\
Feedrate $(\mathrm{mm} / \mathrm{s})$ & 0.015 \\
Ultrasonic power $(\%)$ & 30 \\
\hline
\end{tabular}


The surface roughness in this study was characterized by Ra, average surface roughness. It was measured with a surface profilometer (Surftest-402, Mitutoyo Corporation, Kanagawa, Japan). The test range was set at $4 \mathrm{~mm}$ and cut-off length was set at $0.8 \mathrm{~mm}$. Surface roughness was measured at two locations of the hole, near the entrance side and near the exit side. At each location, four measurements were performed with 90 degrees between two adjacent measurements. Each measurement was repeated twice. The reported Ra value for each location was the average of these eight collected data.

The workpiece material was stainless steel (15-5). Its prosperities are listed in Table 2. The workpiece size was $152 \mathrm{~mm} \times 127 \mathrm{~mm} \times 12.7 \mathrm{~mm}$.

Table 2 Stainless steel properties

\begin{tabular}{ll}
\hline Property & Value \\
\hline Young's modulus $(\mathrm{GPa})$ & 200 \\
Poisson's ratio & 0.28 \\
Yield strength $(\mathrm{MPa})$ & $1000-1100$ \\
Ultimate tensile strength $(\mathrm{MPa})$ & $1100-1200$ \\
Hardness, Rockwell $(\mathrm{C})$ & $35-40$ \\
Thermal conductivity $(\mathrm{W} / \mathrm{m} \cdot \mathrm{K})$ & 20 \\
Density $\left(\mathrm{g} / \mathrm{cm}^{3}\right)$ & 7.8 \\
\hline
\end{tabular}




\section{Experiment results from Test 1}

Test 1 was designed to prevent the tool from grinding the hole surface near the entrance side

while retreating. Only half of the hole (instead of a complete hole) was drilled so that the workpiece could be moved away from the tool after the tool drilled through the workpiece thickness. Figure 7 shows the five stages of this test.

(a) The tool is at its starting position;

(b) Drilling starts;

(c) Drilling ends;

(d) The workpiece is moved away from the tool;

(e) The tool retreats to its starting position without touching the drilled half-hole surface. 


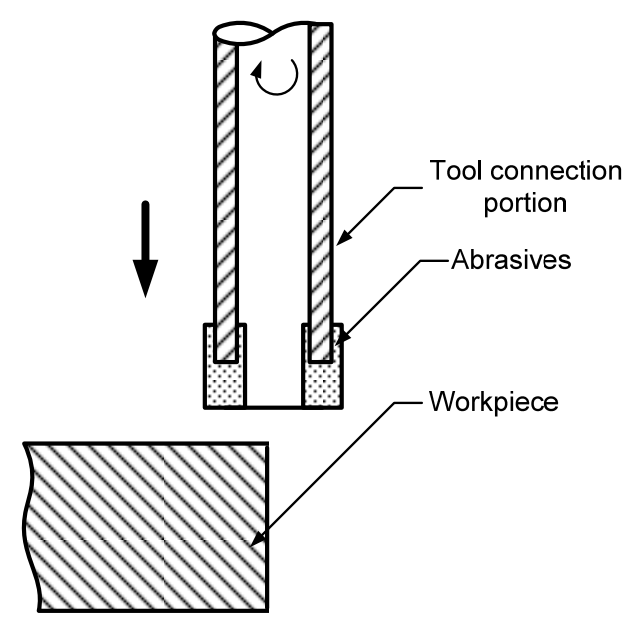

(a) The tool is at its starting position

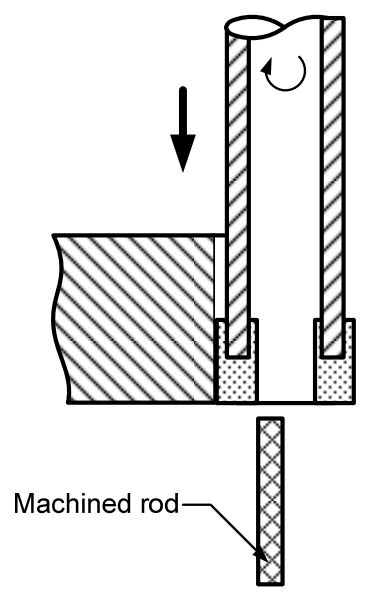

(c) Drilling ends

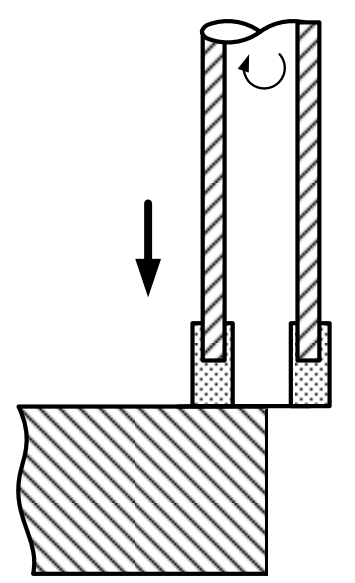

(b) Drilling starts

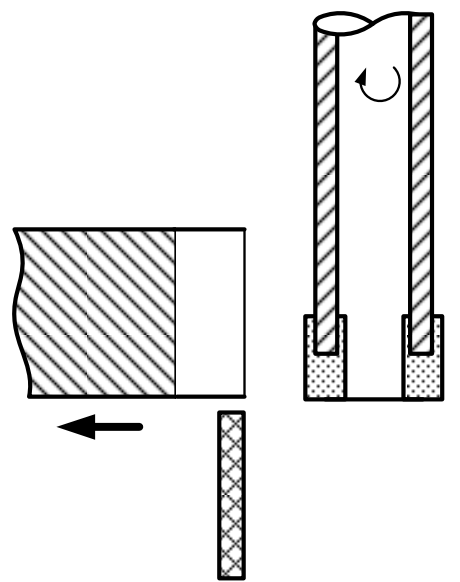

(d) The workpiece is moved away from the tool

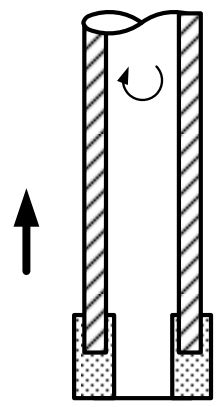

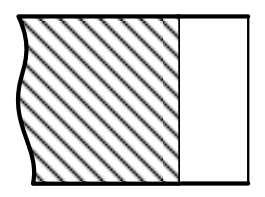

(e) The tool retreats

Figure 7 Illustration of Test 1 for Hypothesis 1. 
If Hypothesis 1 is true, for the machined holes in this test, surface roughness at the two locations (near the entrance side and near the exit side) should be the same (or very similar). Figure 8 shows experiment results from this test. In Figure 8, error bars represent the maximum and minimum surface roughness values of the three holes drilled under each condition. The P-value from the t-test was 0.001 . This means that, at the significance level of $\alpha=0.001$, surface roughness near the entrance side was significantly better than that near the exit side. Therefore, Hypothesis 1 should be rejected.

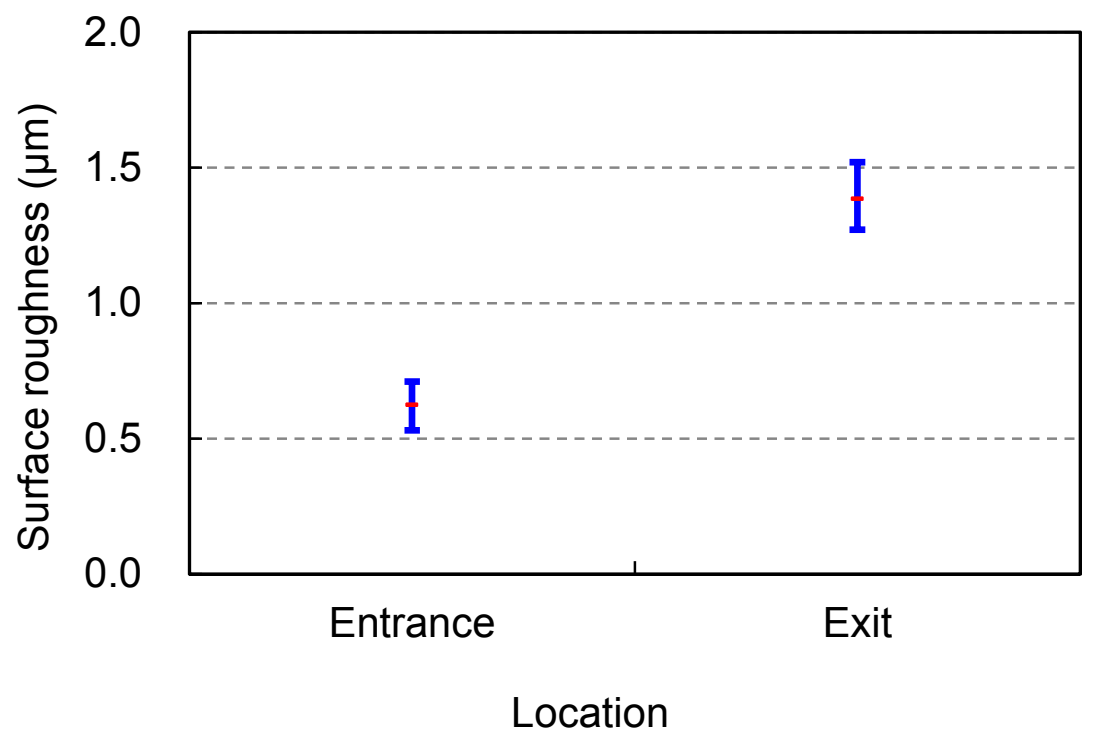

Figure 8 Experimental results of Test 1 for Hypothesis 1. 


\section{Experiment results from Test 2}

Test 2 was also designed to prevent the tool from grinding the drilled hole near the entrance side when it retreats. This was achieved by stopping the tool at the lowest position and removing the workpiece manually. Figure 9 shows the four stages of this test.

(a) The tool is at its starting position;

(b) Drilling starts;

(c) Drilling ends;

(d) The tool stops at its lowest position and the workpiece is removed manually. 


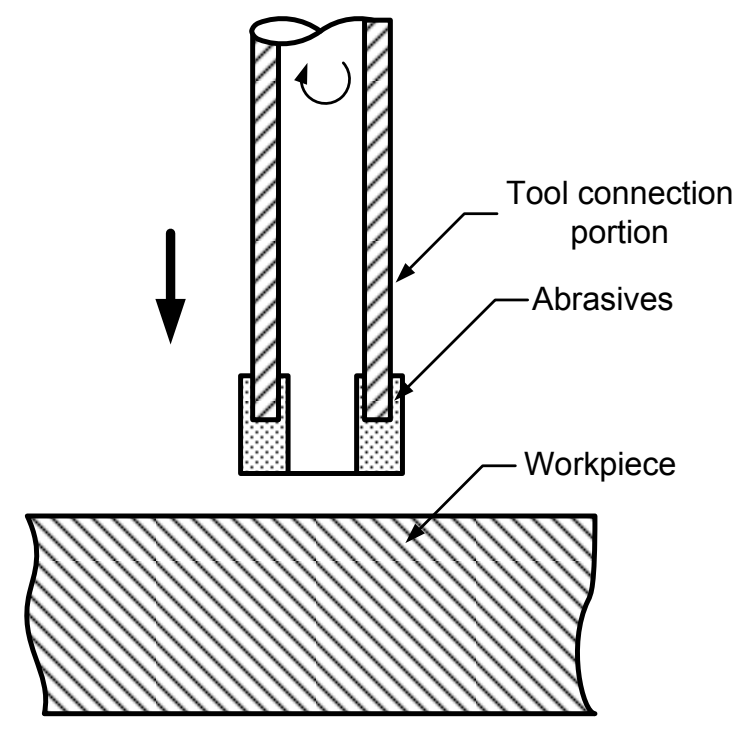

(a) The tool at its starting position

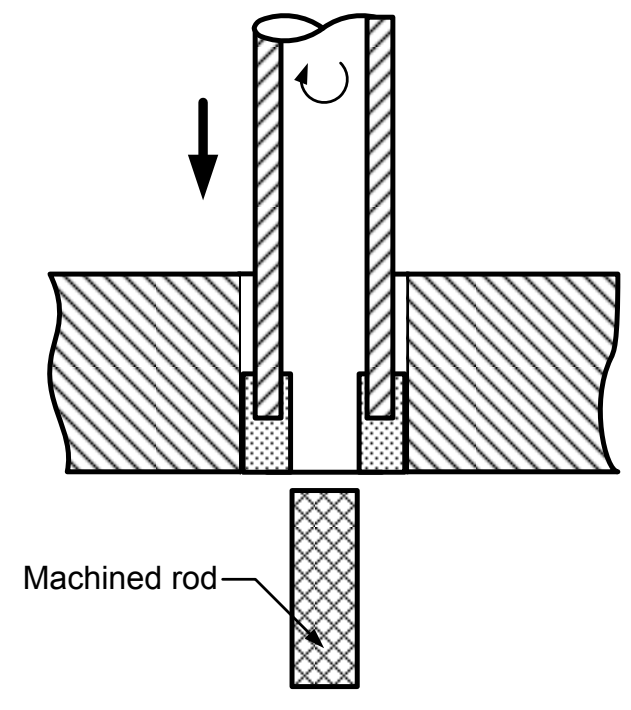

(c) Drill ends

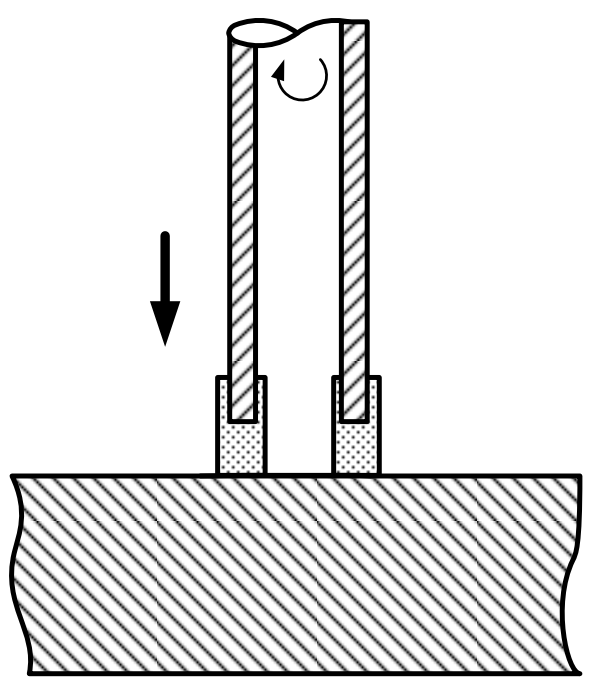

(b) Drilling starts
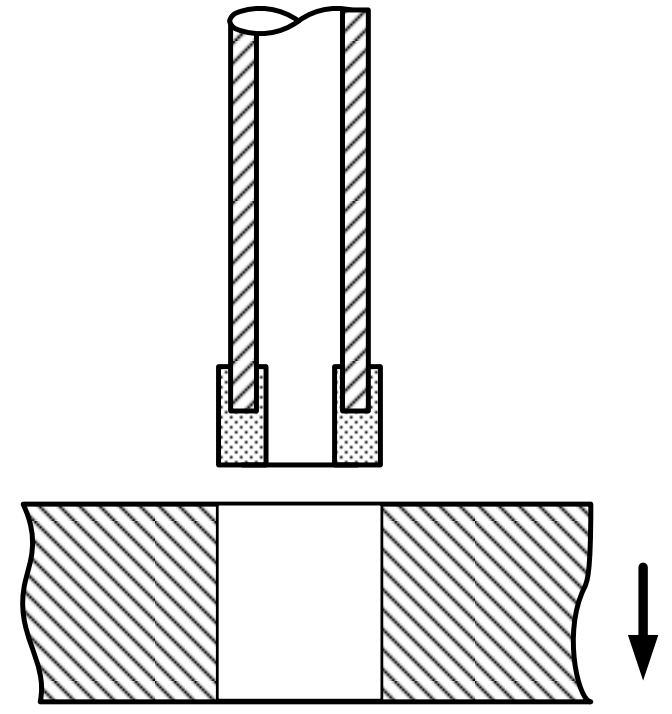

(d) Stopping the tool at its lowest position and removing the wokpiece manually

Figure 9 Illustration of Test 2 for Hypothesis 1.

If Hypothesis 1 is true, for the machined holes in this test, surface roughness at the two locations

(near the entrance side and near the exit side) should be approximately the same. Figure 10

shows the experiment results from this test. The P-value from the t-test was 0.002 . This means 
that, surface roughness near the entrance side was significantly better than that near the exit side at the significance level of $\alpha=0.002$. Therefore, Hypothesis 1 should be rejected.

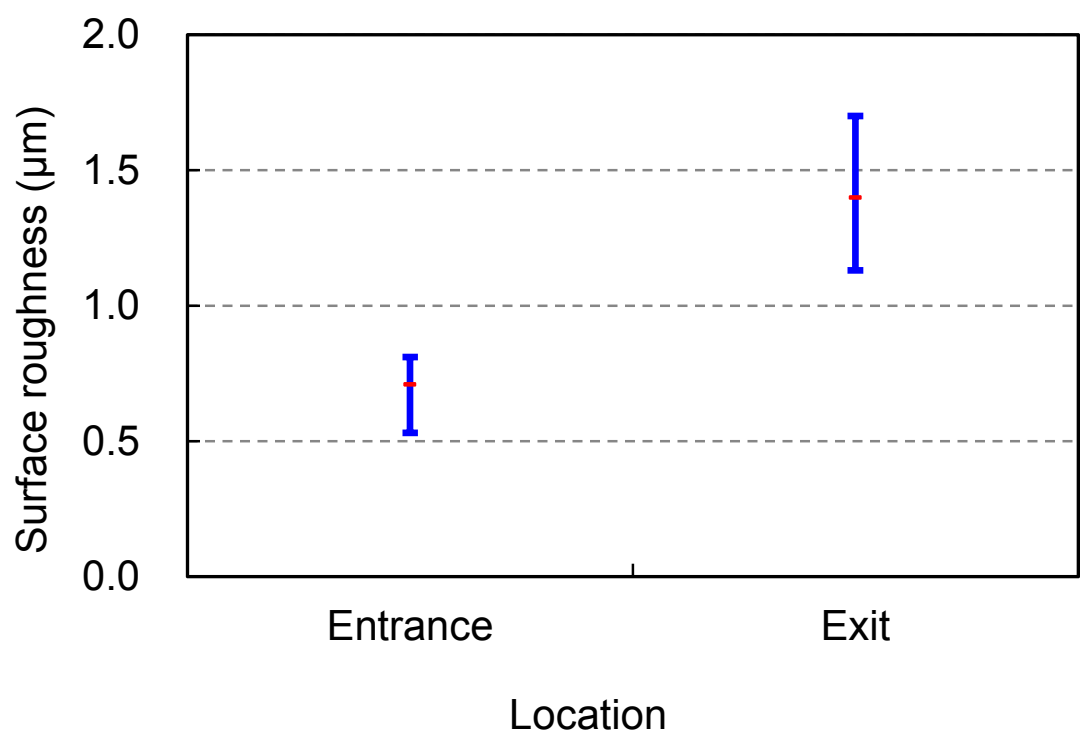

Figure 10 Experimental results of Test 1 for Hypothesis 1.

\section{HYPOTHESIS 2}

\section{Hypothesis}

The workpiece may deform elastically under cutting force, causing the hole diameter near the entrance side become smaller than that near the exit side. If the deformation is large enough, it is possible that the connection portion of the tool will rub the machined hole surface near the 
entrance side, as illustrated in Figure 11. It is hypothesized that the rubbing by the connection portion of the tool might improve the surface roughness near the entrance side.

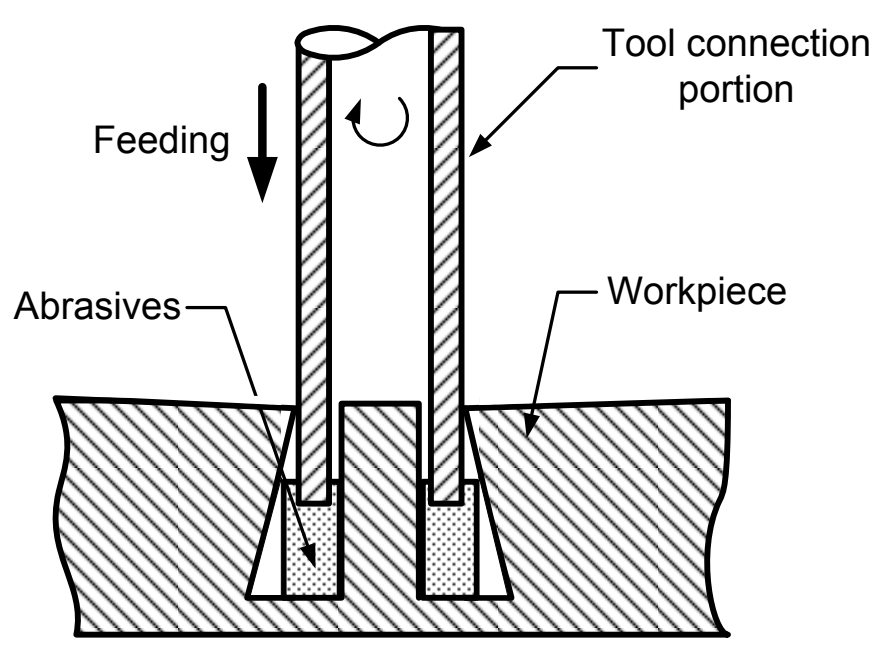

Figure 11 Illustration of Hypothesis 2.

(The magnitude of deformation is greatly exaggerated for illustration purpose)

\section{Hypothesis testing via simulations}

\section{Development of finite element analysis model}

SolidWorks-simulation (SolidWorks Corp., Concord, MA, USA) was used to build a three-dimentional model (as shown in Figure 12) to simulate (calculate) the workpiece deformation during RUM drilling. The workpiece was modeled as a rectangle plate $(152 \mathrm{~mm} \times$ 
$127 \mathrm{~mm} \times 12.7 \mathrm{~mm}$ ) with a cylindrical recess that had an outer diameter (OD) of $9.59 \mathrm{~mm}$ and an inner diameter (ID) of $7.80 \mathrm{~mm}$, the same as the OD and ID of the core drill. Due to the geometric symmetry of the workpiece, only $1 / 4$ of the workpiece was modeled. If viewed on any $\mathrm{X}-\mathrm{Z}$ cross-section (the $\mathrm{X}$ direction was the radial direction of the workpiece and the $\mathrm{Z}$ direction was parallel to the tool axial direction) through the workpiece center, the cylindrical recess became a rectangular recess. Two corners of the rectangular recess were modeled as fillets with a radius of $0.05 \mathrm{~mm}$. The fixture was a platform of a cuboid block with a center hole of $25.4 \mathrm{~mm}$ in diameter. The backside of the workpiece in contact with the fixture surface was constrained from moving in the vertical direction (the $\mathrm{Z}$ direction) by roller restraints. Two symmetry restraints were applied on the two clipping section surfaces. Sliding and rotation in the $\mathrm{X}$ and $\mathrm{Y}$ directions were also constrained.

The cutting depth was the distance between the top surface of the workpiece and the bottom surface of the recess. The range of the cutting depth in the simulation was from 7 to $12 \mathrm{~mm}$ with $1 \mathrm{~mm}$ interval. 


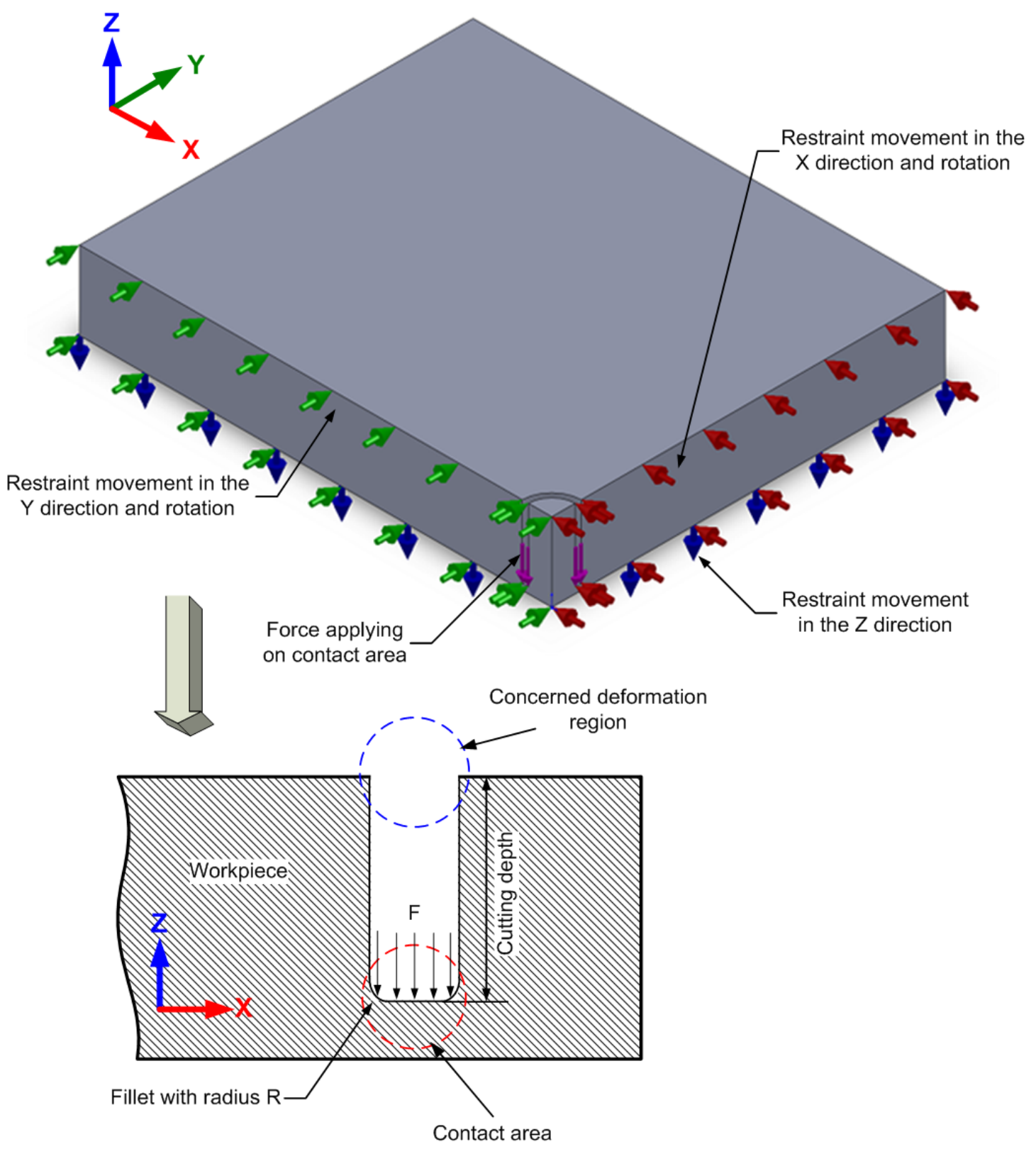

Figure 12 Finite element analysis model of workpiece.

A maximum cutting force of $518 \mathrm{~N}$ (in the $\mathrm{Z}$ direction) was measured from previous experiments

[Cong et al., 2008a]. This maximum force value was applied on the bottom of the rectangular recess. 


\section{Simulation results}

Simulation results show that the maximum displacement (in the horizontal direction toward the hole center) of any point on the machined hole surface near the entrance was less than $10 \mu \mathrm{m}$. It is noted that the gap between the outer diameter of the connection portion of the tool and the outer diameter of the abrasive portion of the tool was $240 \mu \mathrm{m}$ (as illustrated in Figure 13). In other words, the displacement was too small to allow the connection portion of the tool to rub the machined hole surface near the entrance side. Therefore, Hypothesis 2 should be rejected based on the simulation results.

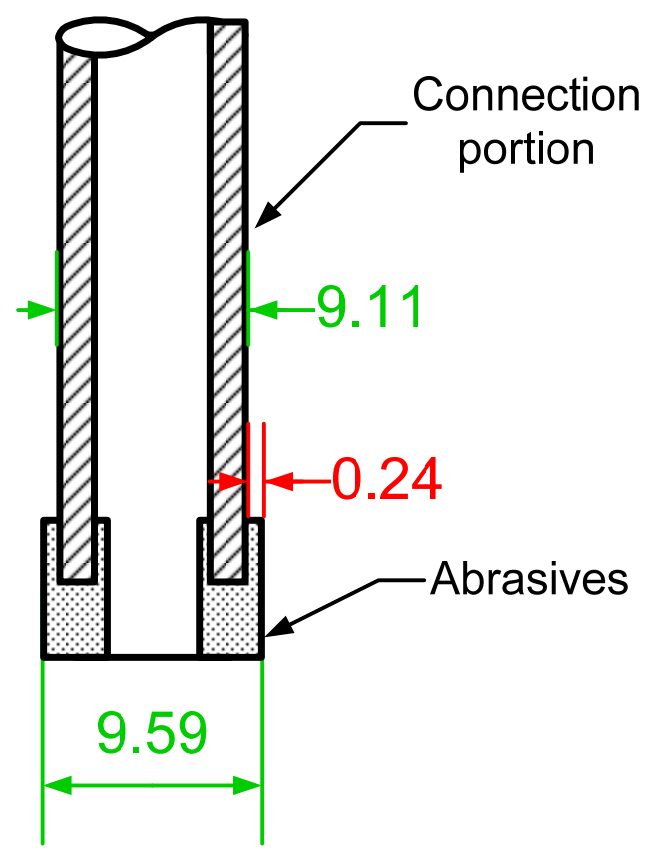

Figure 13 Dimensions of the tools used in experiments (unit: $\mathrm{mm}$ ). (not in scale for illustration purpose) 


\section{HYPOTHESIS 3}

\section{Hypothesis}

As illustrated in Figure 5, as soon as the tool drills through the workpiece thickness, the tool will retreat to its starting position. The location (on the machined hole surface) near the entrance side is ground by the full length of the abrasive portion of the tool, while the location near the exit side is ground by only a fraction of the length of the abrasive portion. It is hypothesized that the difference in the grinding duration by the abrasive portion of the tool causes the difference in surface roughness at the two locations.

\section{Hypothesis testing by experiments}

This test was designed to allow the entire abrasive portion of the tool to grind both locations (near the entrance side and near the exit side). It was done by feeding the tool until the entire abrasive portion went through the workpiece thickness, as illustrated in Figure 14. There are four stages in this test:

(a) The tool is at its starting position; 
(b) Drilling starts;

(c) The tool drills through the workpiece;

(d) The tool retreats after the entire length of the abrasive portion passes through the exit side of the workpiece.

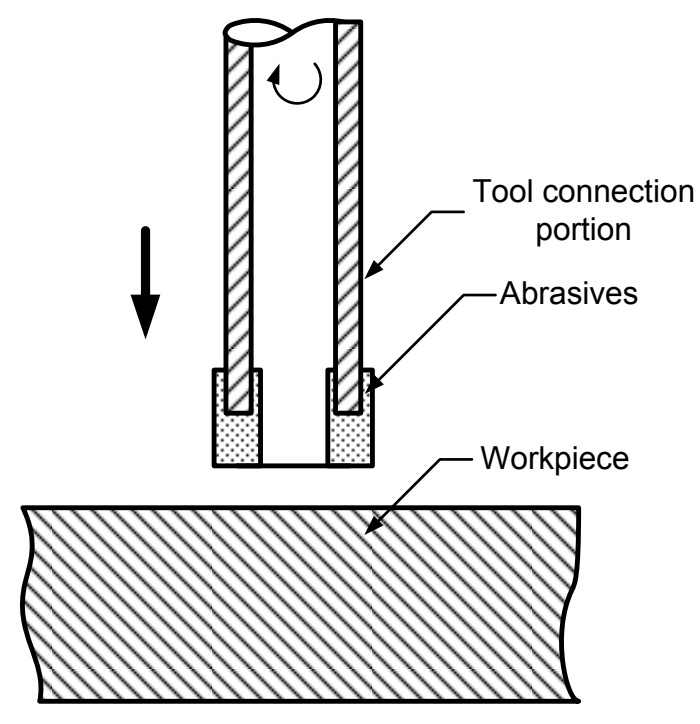

(a) The tool at its starting position

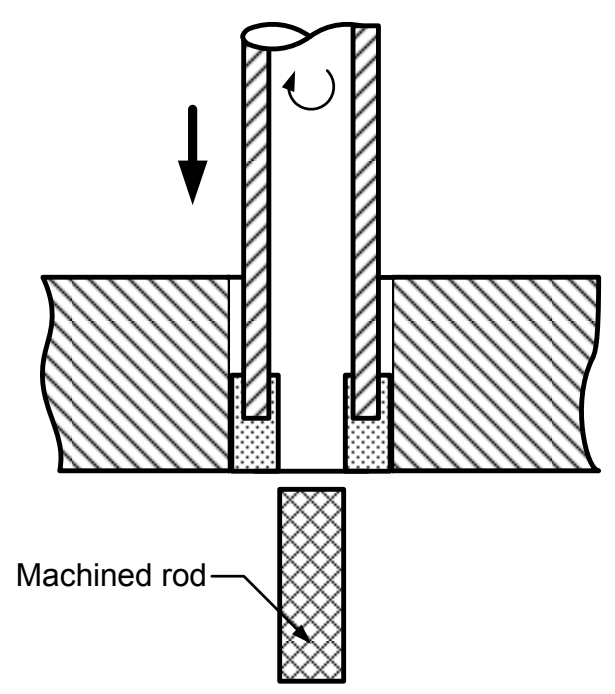

(c) Drilling through the workpiece

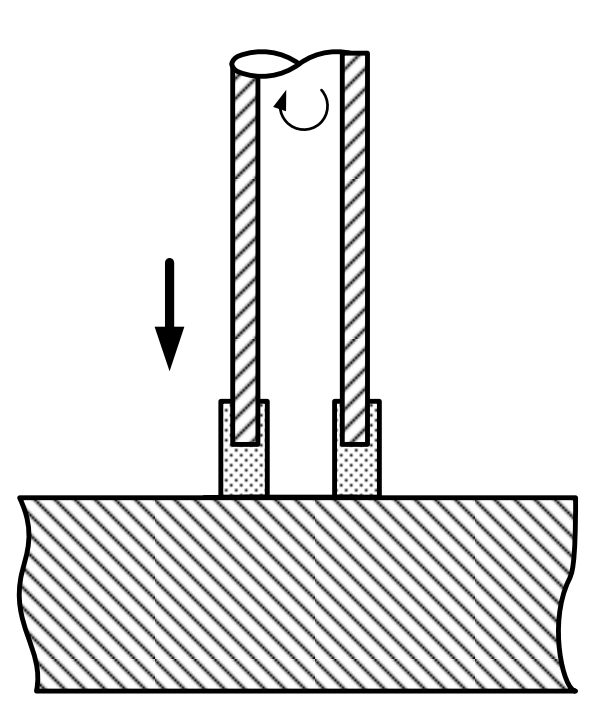

(b) Drilling starts

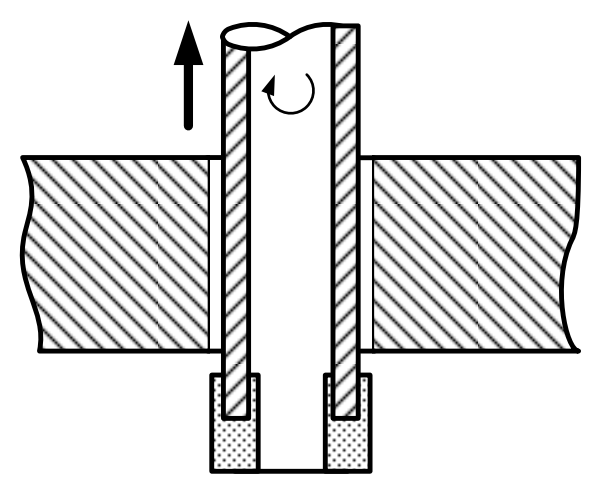

(d) Drilling ends and tool retreats

Figure 14 Illustration of Test 2 for Hypothesis 3. 
In this test, the entire abrasive portion of the tool could grind the entire length of the hole. Hence, the location near the exit side was ground for the same duration of time as the location near the entrance side. If Hypothesis 3 is true, for the holes drilled in this test, surface roughness values at the two locations (near the entrance side and near the exit side) should be approximately the same. As shown in Figure 15, experiment results are consistent with Hypothesis 3. The P-value from the t-test was 0.37 . This means that, at the significance level of $\alpha=0.37$, Hypothesis 3 cannot be rejected.

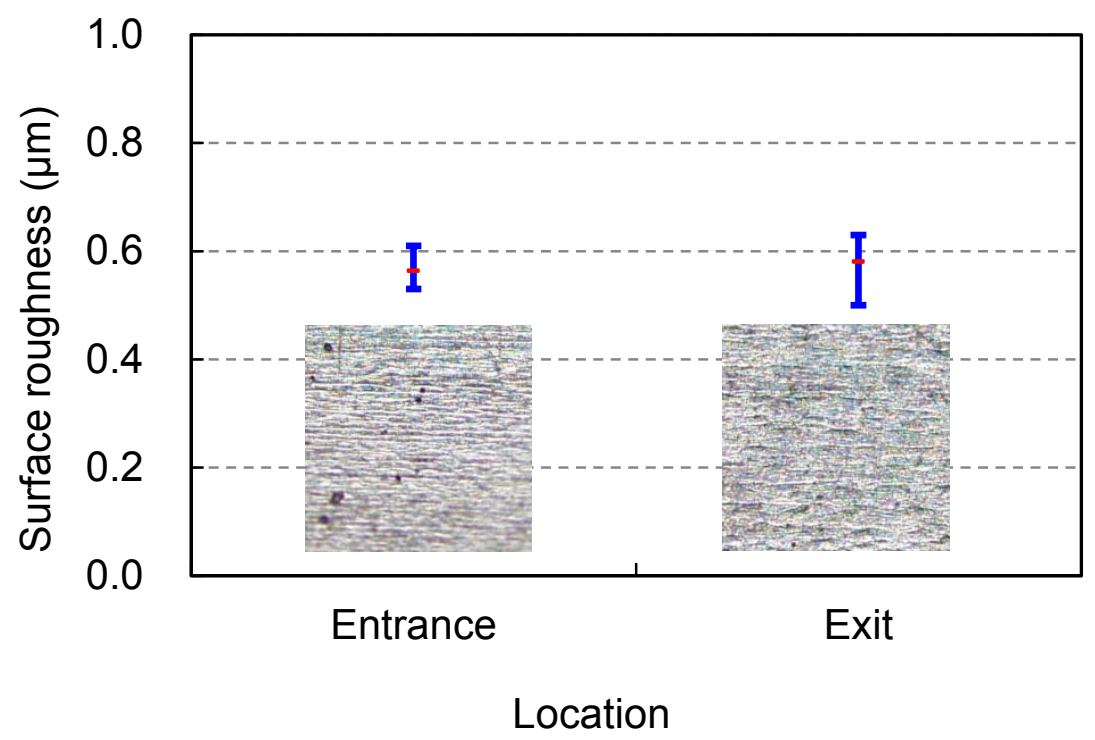

Figure 15 Experimental results of Test for Hypothesis 3

As a reference, Figure 16 shows surface roughness results when drilling with RUM in the 
standard fashion (letting the tool retreat as soon as it cuts through the workpiece thickness). If Hypothesis 3 is true, surface roughness near the exit side on the holes drilled when letting the entire abrasive portion pass through the backside of the workpiece should be much improved over that on the holes drilled when letting the tool retreat as soon as it cuts through the workpiece thickness. This is confirmed by the experiment results (as shown in Figures 15 and 16). The P-value from the t-test (to compare the roughness values near the exit side in Figures 15 and 16) was 0.004 . This means that, at the significance level of $\alpha=0.004$, surface roughness near the exit side on the holes drilled when letting the entire abrasive portion pass through the backside of the workpiece (Figure 15) is significantly different from that on the holes drilled when letting the tool retreat as soon as it cuts through the workpiece thickness (Figure 16).

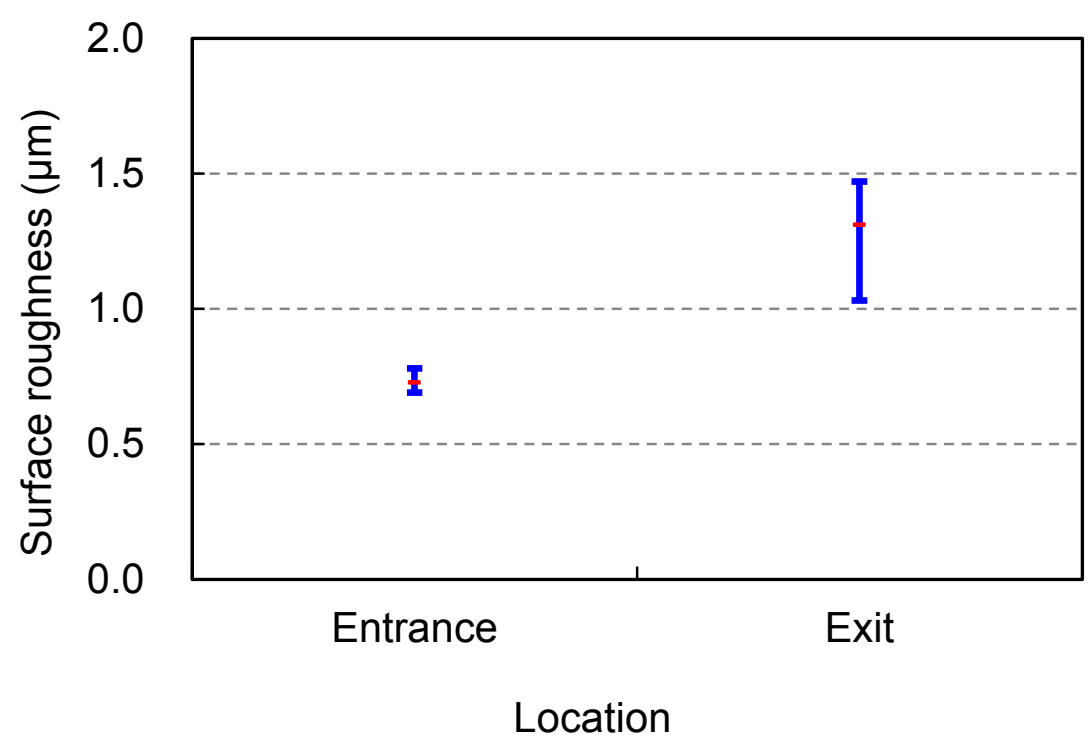

Figure 16 Surface roughness results when drilling with RUM in standard fashion. 


\section{CONCLUSIONS}

Three hypotheses were proposed to explain why surface roughness of the drilled holes near the entrance side is better than that near the exit side in rotary ultrasonic machining. They were tested via experiments and finite element simulations using stainless steel as the example workpiece material.

Based on the results from the experiments and simulations, two hypotheses should be rejected but one cannot be rejected. Therefore, the reason for the difference in surface roughness is: The location near the entrance side was ground longer than the location near the exit side by the abrasive portion of the tool. The above results provide guidance for further improvement of surface roughness of drilled holes with rotary ultrasonic machining (as well as other drilling processes).

\section{ACKNOWLEDGMENTS}

The work was supported by the National Science Foundation through Award CMMI- 0900462.

The authors would like to thank NBR Diamond Tool Corporation for providing the diamond 
tools.

\section{REFERENCES}

[1] Churi, N.J.; Li, Z.C.; Pei, Z.J.; Treadwell, C. (2005) Rotary ultrasonic machining of titanium alloy: a feasibility study. Proceedings of the 2005 ASME International Mechanical Engineering Congress and Exposition, Orlando, FL, USA, November 5-11, 16-2: 885-892.

[2] Churi, N.J.; Pei, Z.J.; Treadwell, C. (2006) Rotary ultrasonic machining of titanium alloy: effects of machining variables. Machining Science and Technology, 10: 301-321.

[3] Churi, N.J.; Pei, Z.J.; Treadwell, C. (2007a) Rotary ultrasonic machining of titanium alloy (Ti-6Al-4V): effects of tool variables. International Journal of Precision Technology, 1: 85-96.

[4] Churi, N.J.; Pei, Z.J.; Treadwell, C. (2007b) Wheel wear mechanisms in rotary ultrasonic machining of titanium. Proceedings of the 2007 ASME International Mechanical Engineering Congress and Exposition (ASME/IMECE), Seattle, WA, USA, November 11-15.

[5] Churi, N.J.; Pei, Z.J.; Treadwell, C.; Shorter, D. (2007c) Rotary ultrasonic machining of 
silicon carbide: designed experiments. International Journal of Manufacturing Technology and Management, 12: 284-287.

[6] Churi, N.J.; Pei, Z.J.; Treadwell, C.; Shorter, D. (2009) Rotary ultrasonic machining of dental ceramics. International Journal of Machining and Machinability of Materials, 6: 270-284.

[7] Cong, W.L.; Pei, Z.J.; Churi, N.; Wang, Q.G. (2009a) Rotary ultrasonic machining of stainless steel: design of experiments. Transactions of the North American Manufacturing Research Institution of SME, 37: 261-268.

[8] Cong W.L.; Pei, Z.J.; Van Vleet, E.; and Wang, Q.G. (2009b) Surface roughness in rotary ultrasonic machining of stainless steels, Proceedings of the IIE Annual Conference and Expo 2009 - Innovations Revealed, Miami, FL,US, May 30 - June 3.

[9] Cong, W.L.; Pei, Z.J.; Deines, T.W; Wang, Q.G. (2010) Rotary ultrasonic machining of stainless steels: empirical study of machining variables. International Journal of Manufacturing Research, 5: 370-386.

[10] Cong, W.L.; Feng, Q.; Pei, Z.J.; Deines, T.W.; Treadwell, C. (2011) Dry machining of carbon fiber reinforced plastic composite by rotary ultrasonic machining: effects of machining variables. Proceedings of the ASME 2011 International Manufacturing Science 
and Engineering Conference (MSEC), Corvallis, OR, June 13-17, 2011.

[11] Jiao, Y.; Hu, P.; Pei, Z.J.; Treadwell, C. (2005) Rotary ultrasonic machining of ceramics: design of experiments. International Journal of Manufacturing Technology and Management, 7: 192-206.

[12] Li, Z.C.; Jiao, Y.; Deines, T.W.; Pei, Z.J. Treadwell, C. (2004) Rotary ultrasonic machining (RUM) on ceramic matrix composites (CMC): designed experiments. Proceedings of the Fifth International Conference on High Temperature Ceramic Matrix Composites (HTCMC-5), Seattle, WA, US, September 12-16.

[13] Li, Z.C.; Jiao, Y.; Deines, T.W.; Pei, Z.J.; Treadwell, C. (2005a) Rotary Ultrasonic Machining of Ceramic Matrix Composites: Feasibility Study and Designed Experiments. International Journal of Machine Tools and Manufacture, 45: 1402-1411.

[14] Li, Z.C.; Pei, Z.J.; Zeng, W.M.; Kwon, P., Treadwell, C. (2005b) Preliminary experimental study of rotary ultrasonic machining on zirconia toughened alumina. Transactions of the North American Manufacturing Research Institution of SME, 33: 261-268.

[15] Li, Z.C.; Pei, Z.J.; Sisco, T.; Micale, A.C.; Treadwell, C. (2007) Experimental study on rotary ultrasonic machining of graphite/epoxy panel. Proceedings of the ASPE 2007 Spring Topical Meeting on Vibration Assisted Machining Technology, Chapel Hill, NC, US, April 
16-17, 52-57.

[16] Prabhakar, D. (1992) Machining Advanced Ceramic Materials Using Rotary Ultrasonic Machining Process. M.S. Thesis: University of Illinois at Urbana-Champaign, IL, US.

[17] Zeng, W. M., Li, Z. C., Pei, Z. J., and Treadwell, C., (2004), Experimental investigation into rotary ultrasonic machining of alumina. Proceedings of the International Mechanical Engineering Congress and Exposition 2004, Anaheim, CA, US, November 13-19. 